\title{
Finite Element Analysis Study of Prototype of a Novel Intramedullary Injectable Bioresorbable Polymer Fixator versus a Volar Plate for Surgical Treatment of Distal Radius Fractures
}

\author{
Adam Zysk, Gladius Lewis* \\ Department of Mechanical Engineering, The University of Memphis, Memphis, USA \\ Email: ^glewis@memphis.edu
}

How to cite this paper: Zysk, A. and Lewis, G. (2017) Finite Element Analysis Study of Prototype of a Novel Intramedullary Injectable Bioresorbable Polymer Fixator versus a Volar Plate for Surgical Treatment of Distal Radius Fractures. World Journal of Engineering and Technology, 5, 648-667. https://doi.org/10.4236/wjet.2017.54054

Received: September 19, 2017

Accepted: October 30, 2017

Published: November 2, 2017

Copyright $\odot 2017$ by authors and Scientific Research Publishing Inc. This work is licensed under the Creative Commons Attribution International License (CC BY 4.0).

http://creativecommons.org/licenses/by/4.0/

\begin{abstract}
Complications and shortcomings of volar plating, which is very widely used for surgical treatment of distal radius fractures, are well known. Thus, there is scope for alternative innovative surgical methods. In the present work, we used the finite element analysis method to compare the biomechanical performance of a model of a construct comprising a simulated distal radius fracture considered fixated using a notional intramedullary injectable bioresorbable polymer-bioresorbable balloon osteosynthesis system ("fixator") versus using a commercially-available volar locking plate (VP). The biomechanical parameters determined were longitudinal stiffness and factor of safety under each of the applied loads. For the fixator model, 1) each of the biomechanical parameters was markedly influenced by fracture gap fill ratio (FGFR) (defined as the proportion of the volume of the fracture gap that is considered occupied by the expanded polymer-filled balloon) but not by modulus of elasticity assigned to the polymer; 2) with FGFR $=100 \%$, stiffness was comparable to that of the Ti-6Al-4V alloy VP construct model; and 3) stiffness was within the range of literature values for stiffness of constructs comprising simulated fractures in fresh cadaveric distal radii fixated using metal volar locking plate. These results suggest that the fixator may be an alternative modality to metal volar plating and, as such, deserves further evaluation.
\end{abstract}

\section{Keywords}

Distal Radius Fracture, Volar Locking Plate, Intramedullary Fixation, Finite Element Analysis 


\section{Introduction}

Distal radius fractures (DRFs) are a common occurrence, by some reports accounting for $\sim 17 \%$ of all fractures and $\sim 8 \%$ of all bony injuries presented in emergency rooms/departments [1] [2]. There is a very large and diverse assortment of treatment/management modalities for these fractures. Examples are cast immobilization only; closed reduction and fixation with percutaneous Kirschner wires only; and open reduction and internal fixation with a volar locking plate, dorsal locking plate, percutaneous Kirschner wires in combination with a non-bridging cross-pin fixator, a system comprising an expandable intramedullary cage and fragment-specific screw fixation, intramedullary nailing, or a photodynamic system (comprising a light-curable polymer contained in an inflatable balloon catheter) [3] [4] [5]. For a given fracture type, there is lack of consensus on the optimal treatment modality [4] [6] [7] [8] [9]. Nonetheless, for certain types, the volar locking plate is very widely used [6] [7] [8]. In fact, some have referred to this system as becoming "the treatment of choice" in cases where surgical treatment is deemed appropriate [9]. However, complications after fixation with this system, such as rupture of tendon(s), and its shortcomings, such as delay in wound healing, are well known [10]. Thus, there is scope for development of a new generation of innovative modalities as an alternative to the volar locking plate system.

In our recent contribution, we presented the conceptual features of one such modality, namely, the prototype of a novel intramedullary injectable bioresorbable polymer-bioresorbable balloon osteosynthesis system (for short, "injectable bioresorbable polymer fixator") and results of an in vitro experimental biomechanical evaluation of a construct that comprised a simulated fracture created in a synthetic distal radius and fixated using the fixator [11]. In brief, it is envisaged that using the fixator would involve creating an entry portal into the fractured bone, using a flexible cannulated drill to prepare the intramedullary canal, inserting a compliant balloon catheter into the bone, reducing the fracture, injecting a bioresorbable polymer into the balloon, expanding the balloon to fully conform to the shape of the canal, and allowing the polymer to cure. In that study, we found that each of the determined biomechanical parameters of a construct that included the fixator was comparable to that when fixation was with a commercially-available volar locking plate [11].

The notion of an injectable bioresorbable fixator is a very recent addition to the literature. As such, a parametric biomechanical study involving the fixator by itself and, more importantly, in comparison with a volar locking plate is lacking. The finite element analysis (FEA) method is particularly suited to this type of work. Thus, the purpose of the present study was to use the FEA method to perform a parametric biomechanical study of models of these two types of constructs.

\section{Materials and Methods}

\subsection{Intact Model}

To obtain the intact solid model, a statistically-averaged three-dimensional solid 
model of the bony anatomy of the intact distal radius [12] was exported into a commercial-available solid model software package (NX (Siemens Plano, TX, USA), scaled, and, then, divided into cortical bone and cancellous bone sections using a ratio of $\sim 1: 5$, respectively [13].

FEA using this solid model was carried out in four steps (Figure 1).

In the first step, the intact solid model was exported into a commercially-available finite element analysis package (NX NASTRAN; MSC Software Corp., Newport Beach, CA, USA), where it was meshed using 2 mm-thick four-noded tetrahedral elements; a surface-to-surface gluing contact parameter was inserted at the interface of the cancellous bone and the cortical bone, in order to prevent movement between the meshes of these regions at the interface; values were assigned to the elastic moduli and Poisson's ratios of the cortical bone and the cancellous bone (Table 1); and the model was constrained in both rotation and translation at its most proximal location. For load application, a point on the articular surface collinear with the intramedullary canal was defined and, then, a second point collinear with but $5 \mathrm{~mm}$ above the first point was defined and joined by rigid beam elements to distribute the load (100 N) to a single point of contact, along the vector defined by the two points of the elements.

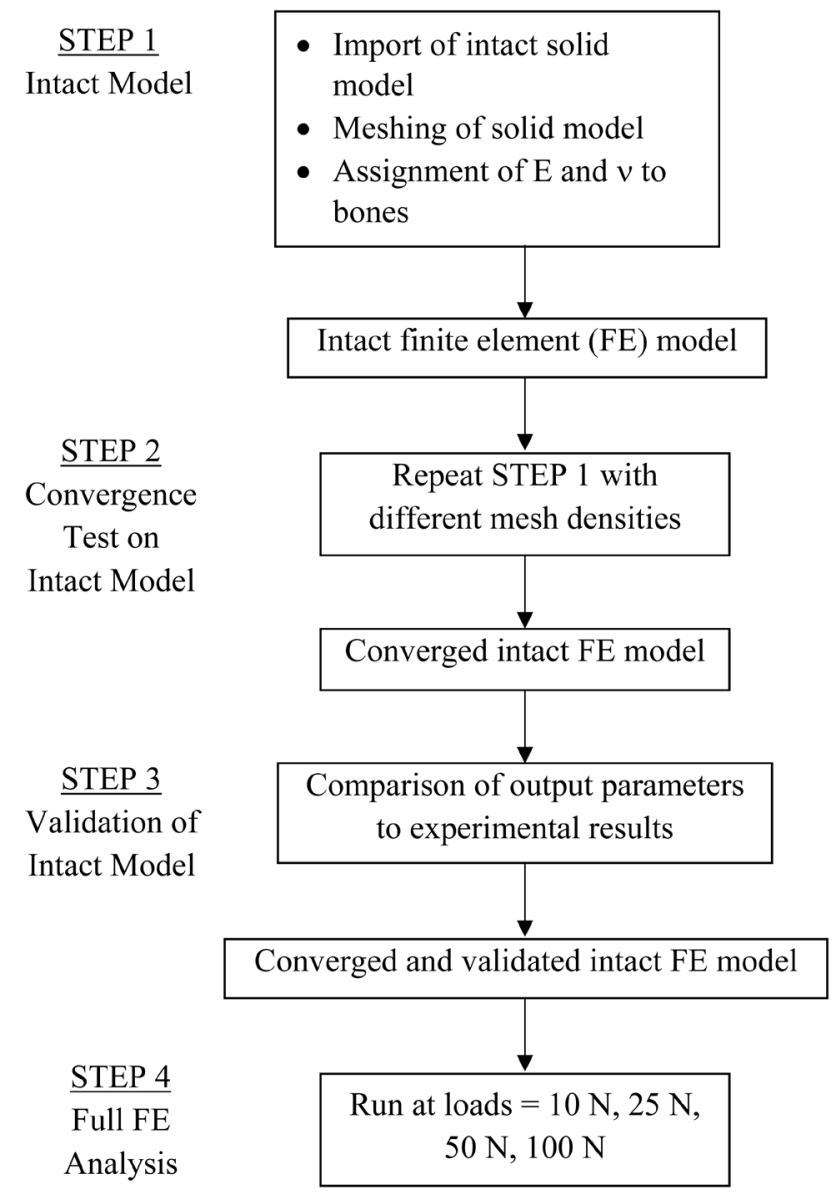

Figure 1. Flow chart of the steps used to perform the finite element analysis (E: modulus of elasticity; v: Poisson's ratio). 
Table 1. Values of the elastic constants and compressive yield strength of the materials used in the FEA of the various models.

\begin{tabular}{|c|c|c|c|}
\hline Tissue/material & Modulus of elasticity (MPa) & Poisson's ratio & Compressive yield strength (MPa) \\
\hline \multicolumn{4}{|l|}{ INTACT Model } \\
\hline Cancellous bone $^{\mathrm{a}}$ & 1300 & 0.3 & \\
\hline Cortical bone $^{a}$ & 17,000 & 0.3 & \\
\hline \multicolumn{4}{|c|}{ INJECTABLE BIORESORBABLE POLYMER FIXATOR CONSTRUCT Model } \\
\hline Case 1 Polymer A; FGFR ${ }^{\mathrm{b}}=0 \%$ & 3500 & 0.3 & 35 \\
\hline \multicolumn{4}{|l|}{ Case 2 Polymer A; FGFR = 50\% } \\
\hline \multicolumn{4}{|l|}{ Case 3 Polymer A; FGFR = 100\% } \\
\hline Case 4 Polymer B; FGFR $=0 \%$ & 4500 & 0.3 & 35 \\
\hline \multicolumn{4}{|l|}{ Case 5 Polymer B; FGFR $=50 \%$} \\
\hline \multicolumn{4}{|l|}{ Case 6 Polymer B; FGFR $=100 \%$} \\
\hline Case 7 Polymer C; FGFR = 0\% & 5000 & 0.3 & 35 \\
\hline \multicolumn{4}{|l|}{ Case 8 Polymer C; FGFR = 50\% } \\
\hline \multicolumn{4}{|l|}{ Case 9 Polymer C; FGFR $=100 \%$} \\
\hline \multicolumn{4}{|c|}{ VOLAR PLATING SYSTEM CONSTRUCT model } \\
\hline Case 1316 stainless steel $^{\mathrm{c}}$ & 206,000 & 0.29 & 450 \\
\hline Case $2 \mathrm{Ti}-6 \mathrm{Al}-4 \mathrm{~V}$ alloy ${ }^{\mathrm{c}}$ & 110,000 & 0.34 & 830 \\
\hline $\begin{array}{l}\text { Case } 3 \text { Carbon fiber-reinforced PEEK } \\
\text { (load applied parallel to fibers })^{\mathrm{d}}\end{array}$ & 4300 & 0.3 & 180 \\
\hline 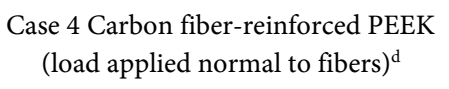 & 2600 & 0.3 & 145 \\
\hline
\end{tabular}

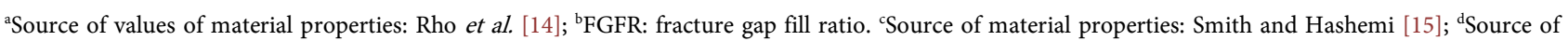
material properties: Rasheva et al. [16].

The output parameters obtained were longitudinal displacement of the construct (and, hence, the maximum displacement) and the von Mises stress distribution contour (and, the maximum von Mises stress). Von Mises stress is a composite of the net normal and net torsional stresses in a component, developed in response to the applied loadings. Normal stresses are due to axial force(s) and/or bending moment(s) and torsional stress are due to direct shear force and/or torsional moment(s) (torque(s)). In the second step (convergence exercise), the aforementioned steps were repeated using other mesh densities (but with the same element type). The purpose here was to obtain a convergence point, this being the point at which successive change in mesh density produced a change of $<5 \%$ in each of the output parameters. The resulting model is termed, "the converged intact finite element model." In the third step (validation exercise), the output parameters obtained using the converged intact finite element model were compared to experimental results obtained using fresh cadaveric distal radii, as reported in the literature. At that point, if agreement between the two sets of results was deemed unacceptable, adjustments were made to the solid model and the first two steps were repeated until excellent agreement 
was achieved, thereby yielding the converged and validated intact model (INTACT Model). In the fourth step, the INTACT Model was subjected to loads $(10 \mathrm{~N}, 25 \mathrm{~N}, 50$, and $100 \mathrm{~N})$ and, under each of these loads, the longitudinal displacement contour of the model (and, hence, the maximum displacement) and the von Mises stress distribution contour (and, hence, the maximum von Mises stress) were obtained. Longitudinal stiffness of the model was determined as the slope of the best-fit linear plot of load versus maximum longitudinal displacement.

\subsection{Simulated Fractured and Fracture-Fixated Models}

The simulated fracture solid model was obtained by copying INTACT Model and placing a planar gap in it, $4 \mathrm{~mm}$ wide and centered $25 \mathrm{~mm}$ from the most distal portion of the model. This model is designated FRACTURE Model.

Three steps were taken in constructing the solid model of the construct comprising the simulated fracture and the fixator. First, FRACTURE Model was copied and then an intramedullary canal (diameter and length $=5.00 \mathrm{~mm}$ and 9.85 $\mathrm{mm}$, respectively) [17] was extruded and then subtracted from it. Second, a rod, with diameter $=5 \mathrm{~mm}$ and length $=75 \mathrm{~mm}$ (considered fabricated using a bioresorbable polymer), was placed in the canal. Third, the region between the fracture gap and the intramedullary rod was considered filled with a plug of the same bioresorbable polymer. This model is designated FIXATOR CONSTRUCT Model. 3 variants of this Model were created, the difference being in the fracture gap fill ratio, defined as the proportion of the volume fracture gap that is filled with the polymer-filled balloon. Each of these variants was meshed using the same method as was used for INTACT Model, with one addition, this being insertion of a surface-to-surface gluing contact parameter at the interface between the intramedullary rod and the cancellous bone in order to prevent movement of the meshes of these two regions at the interface. Furthermore, for each of these three variants, three different moduli of elasticity were assigned to the bioresorbable polymer (Table 1). Thus, 9 FEA cases were run (Table 1), using four loads $(10 \mathrm{~N}, 25 \mathrm{~N}, 50 \mathrm{~N}$, and $100 \mathrm{~N})$ in each case. The output parameters in each combination of case and applied load were the longitudinal displacement contour (and, hence, maximum displacement) and the von Mises stress contour (and, hence, maximum von Mises stress). From the former parameter, longitudinal stiffness was calculated as described earlier and from the latter parameter the factor of safety against elastic failure of the model was calculated as the ratio of the compressive strength of the assigned injected bioresorbable polymer (Table 1) to the maximum von Mises stress.

The solid model of the construct containing the simulated fracture and the volar locking plate (VOLAR PLATING CONSTRUCT Model) was obtained by copying FRACTURE Model and then positioning the volar plating system (plates and screws) having the same features as those of a commercially-available Ti-6Al-4V alloy fixed-angle metal volar locking plate system (D-RAD SmartPack; Smith \& Nephew Orthopeadics, Memphis, TN, USA) on the distal aspect 
of the volar rim, as close to but not exceeding the watershed line. A small gap was left between the bone and the plate to represent the physical contact limitations of an actual bone plate and the different patient anatomies. The variable-angle feature of the locking holes was removed. Screws were then projected from the locking holes through the bone. Only locking holes were considered for screw placement, resulting in six screws filling the head of the plate and three screws in the shaft. (The slot does not contain locking features.) The model was meshed, as described above, but with the additional feature of a surface-to-surface gluing contact inserted at each of the following interfaces: volar plate-locking screw; locking screw-cancellous bone; and cortical screw-cortical bone. FEA was conducted on four variants of the Model, the difference being in the material assigned to the plate and the screws (and, hence, moduli of elasticity and Poisson's ratios for these materials; see Table 1). For each of the cases run, the output parameters were the same as for the FIXATOR CONSTRUCT Model cases, but with factor of safety calculated as the ratio of the compressive strength of the assigned plate/screws material (Table 1) to the maximum von Mises stress.

\section{Results}

All the converged finite element models, sample longitudinal displacement contour, and sample von Mises stress distribution contour are given in Figures 2-5. For fresh cadaveric intact distal radii, experimental result for compressive stiffness given in the literature is $379 \pm 146 \mathrm{~N} \cdot \mathrm{mm}^{-1}$ [18], while, for INTACT Model, it was $497 \mathrm{~N} \cdot \mathrm{mm}^{-1}$, indicating that INTACT Model was validated.

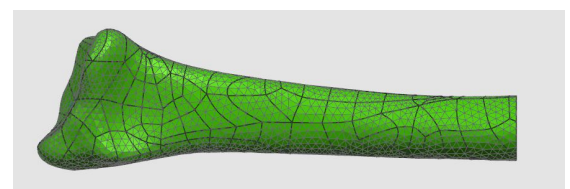

(a)

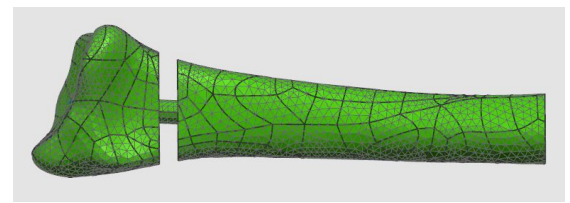

(b)

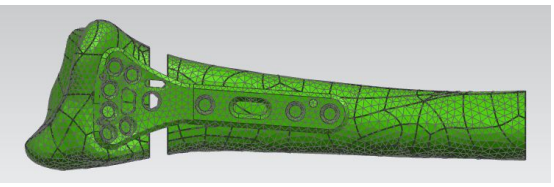

(c)

Figure 2. Finite element mesh of the intact distal radius model (INTACT model) (a); the construct comprising distal radius with simulated fracture fixated using the notional intramedullary injectable polymer fixator (Injectable Polymer Fixator Construct Model) (b); and the construct comprising distal radius with simulated fracture fixated using a commercially-available $\mathrm{Ti}-6 \mathrm{Al}-4 \mathrm{~V}$ alloy fixed-angle volar plating system (Volar Plate Construct Model) (c). 


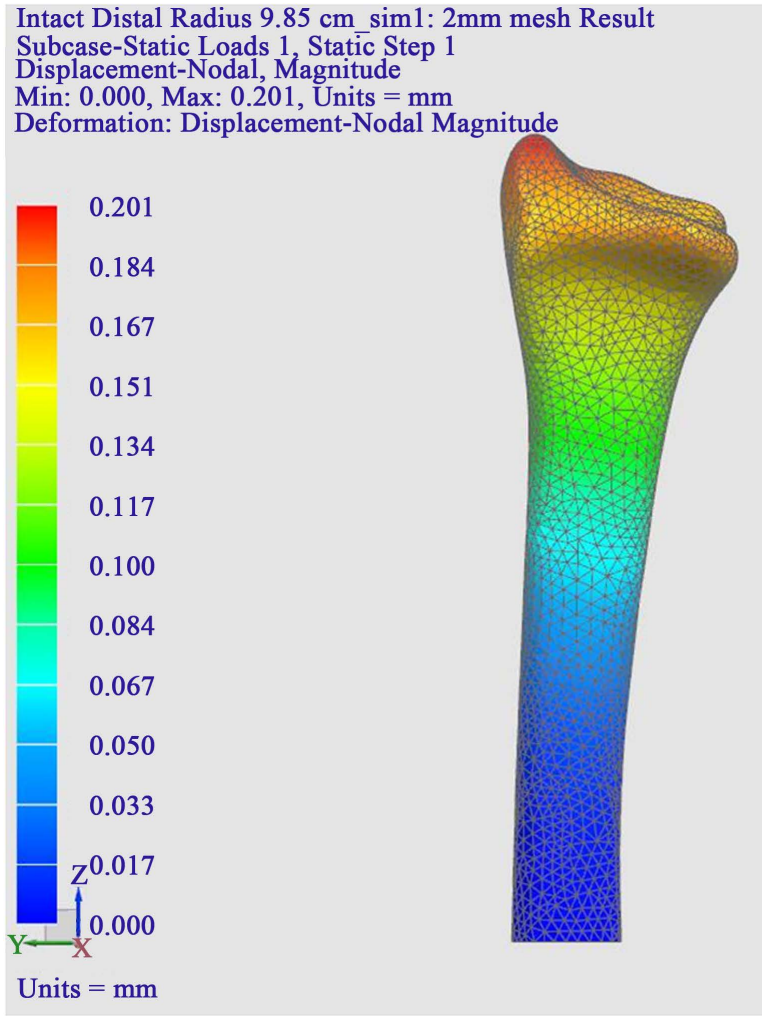

(a)

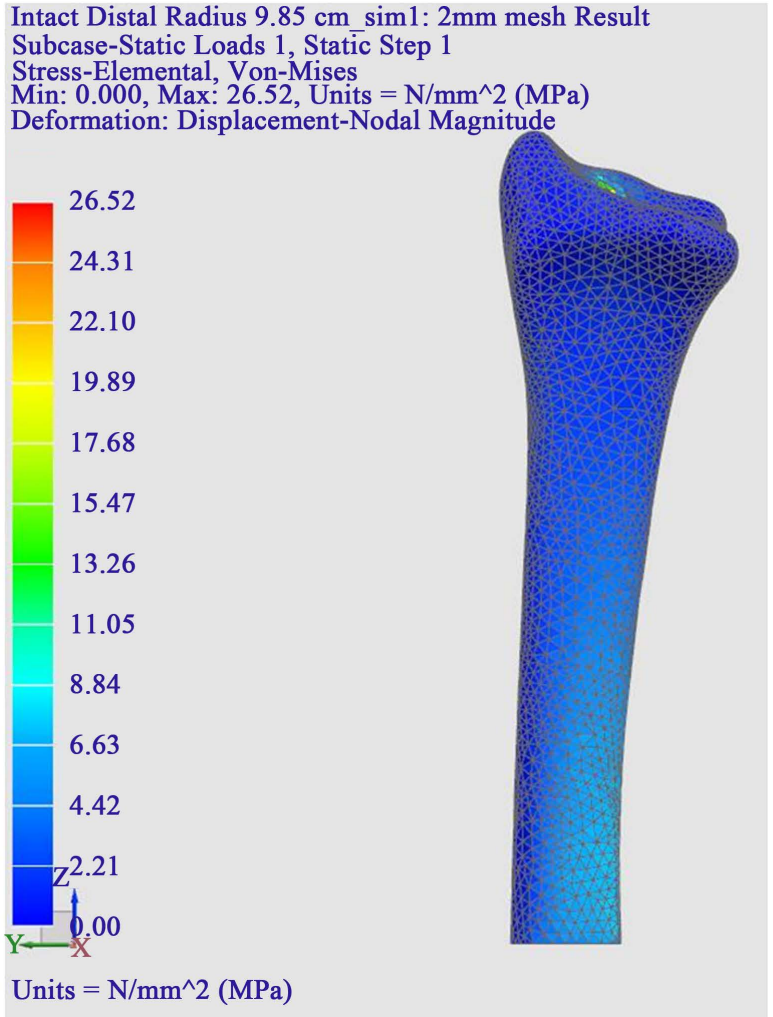

(b)

Figure 3. Longitudinal displacement contour (a) and von Mises stress distribution contour (b) for INTACT Model, under applied compressive force of $100 \mathrm{~N}$. 


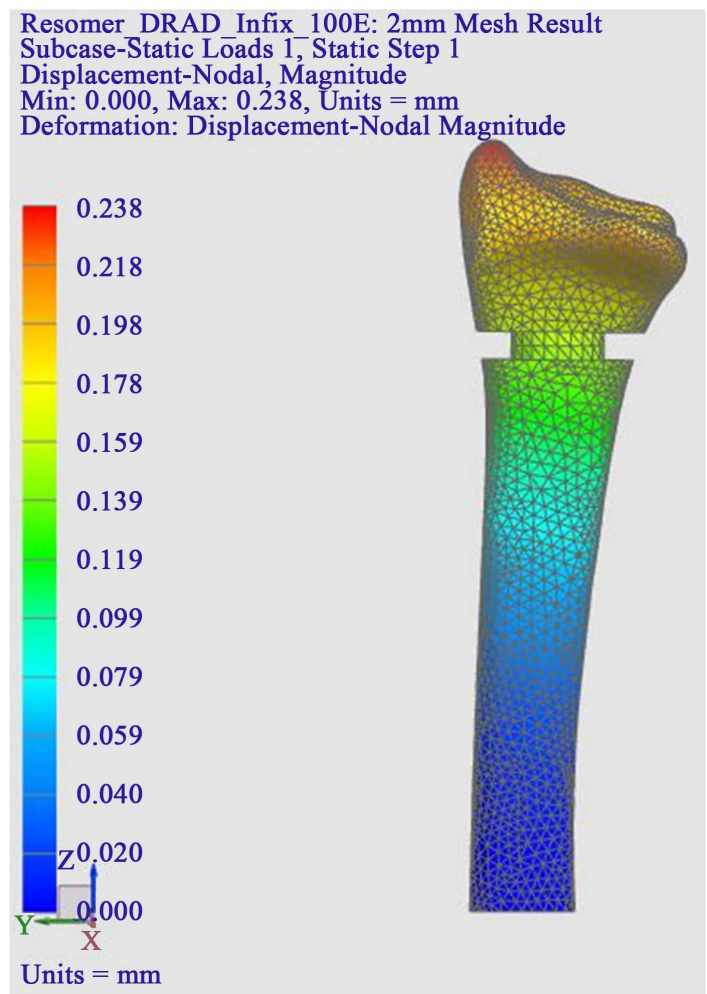

(a)

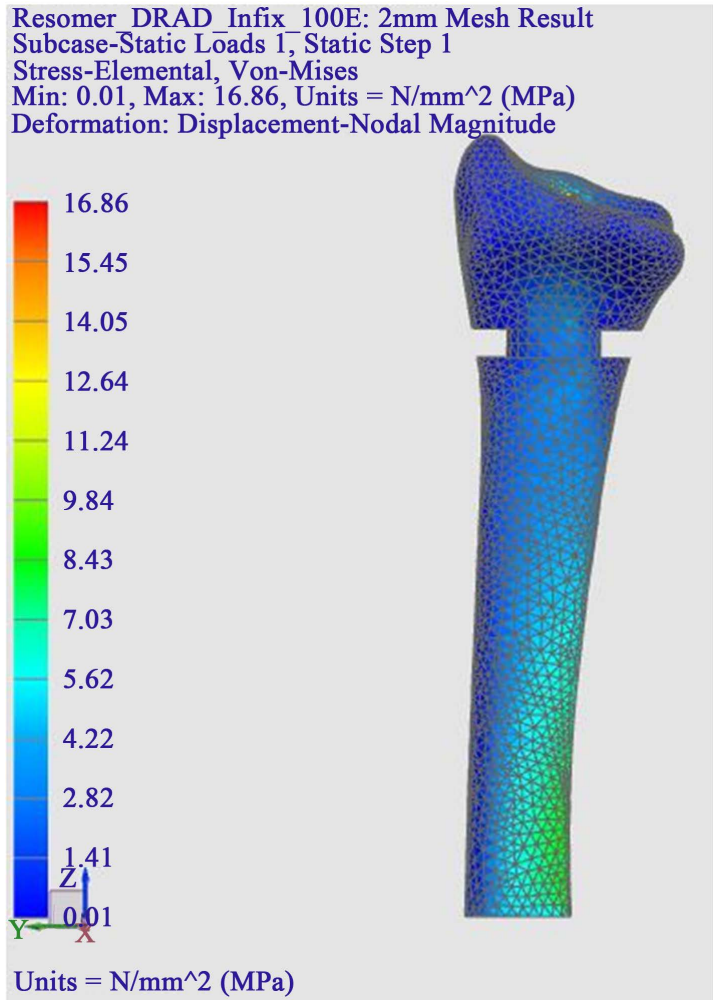

(b)

Figure 4. Longitudinal displacement contour (a) and von Mises stress distribution contour (b) for Injectable Polymer Construct Model (Biopolymer C; fracture gap fill ratio = $100 \%$ ), under compressive force of $100 \mathrm{~N}$. 


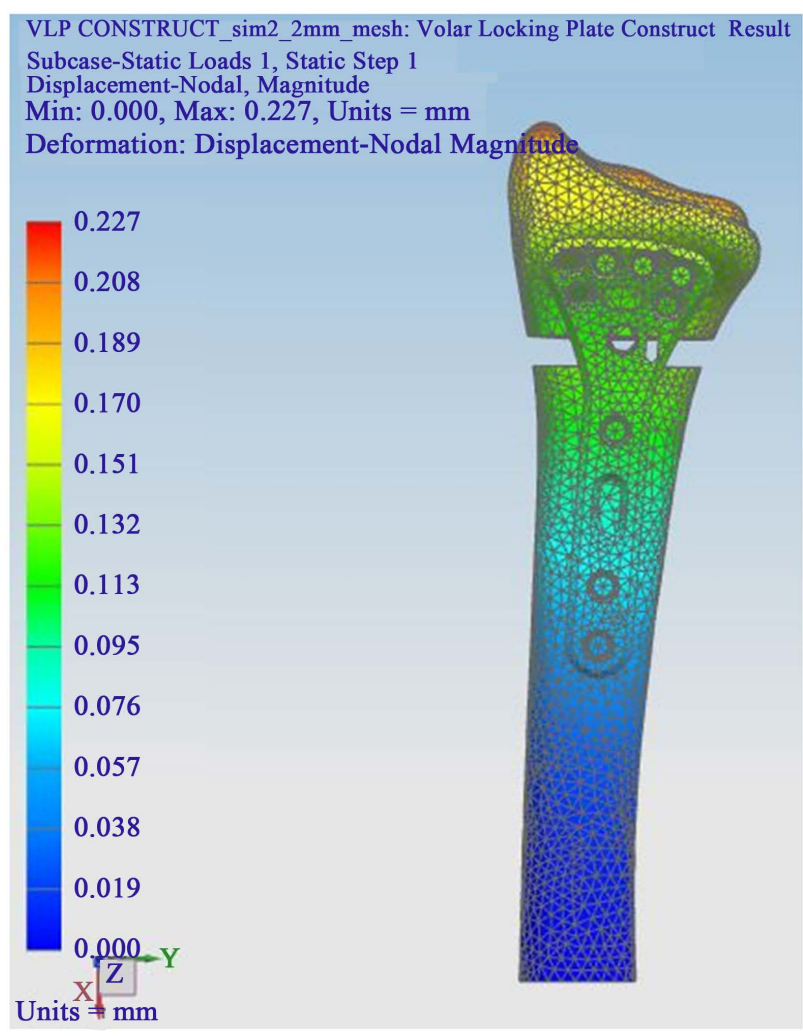

(a)

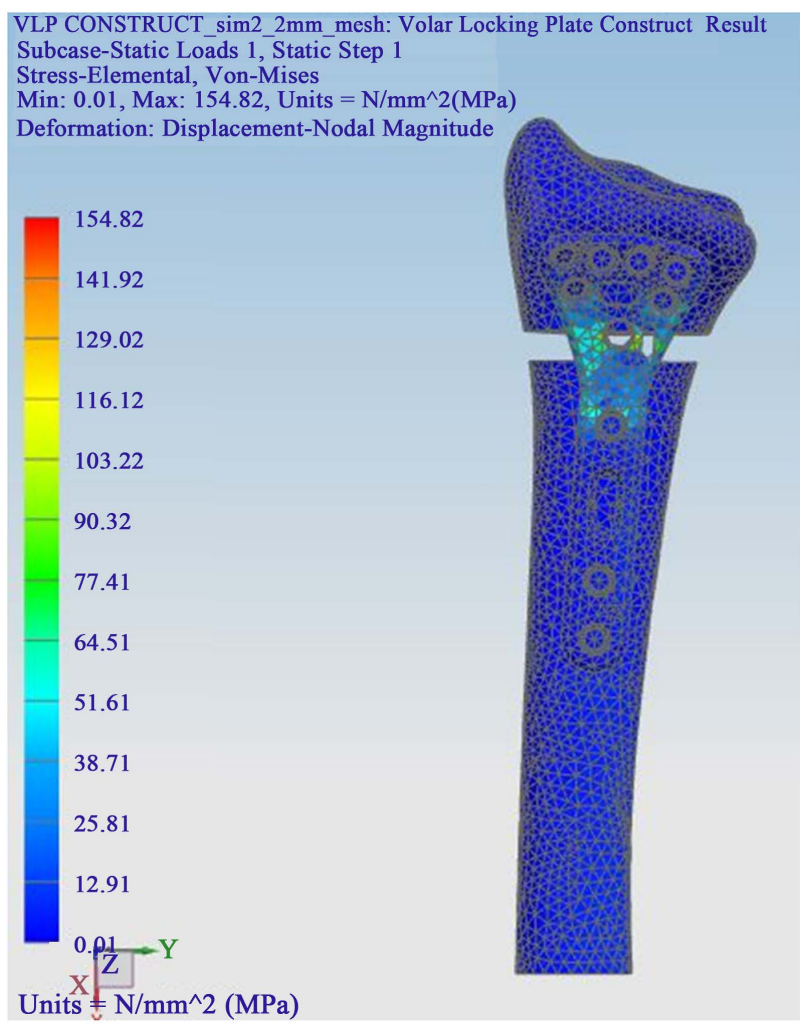

(b)

Figure 5. Longitudinal displacement contour (a) and von Mises stress distribution contour (b) for Volar Plate Construct Model, under compressive force of $100 \mathrm{~N}$. 
It is seen (Figure 6 and Figure 7) that: 1) in FIXATOR CONSTRUCT Model, with increase in the assigned modulus of elasticity of the polymer, for a given fracture gap fill ratio, the increases in stiffness is small and computed factor of safety is, essentially, constant; 2) in FIXATOR CONSTRUCT Model, with increase in fracture gap fill ratio, for a given assigned modulus of elasticity of the polymer, increase in stiffness is very marked while computed factor of safety increased markedly at first but, subsequent, becomes practically constant; 3) in VOLAR PLATING CONSTRUCT Model, there is clear demarcation between metal variants and composite material variants, with both stiffness and computed factor of safety being substantially higher in the former variants; 4) stiffness of FIXATOR CONSTRUCT Model (having fracture fill gap ratio $=100 \%$, regardless of the assigned elastic modulus of the polymer, was comparable to that of Ti-6Al-4V alloy Volar Plating Construct Model; and 5) computed factor of safety of FIXATOR CONSTRUCT Model with fracture gap fill ratio $=50 \%$ or $100 \%$, regardless of the assigned modulus of elasticity of the polymer, is comparable to that of stainless steel Volar Plating Construct Model.

\section{Discussion}

The optimum treatment method for a given DRF type remains a very controversial subject [6] [7] [8] [9]. Although volar plating is the most popular surgical modality [9], complications, such as carpal tunnel syndrome and rupture of
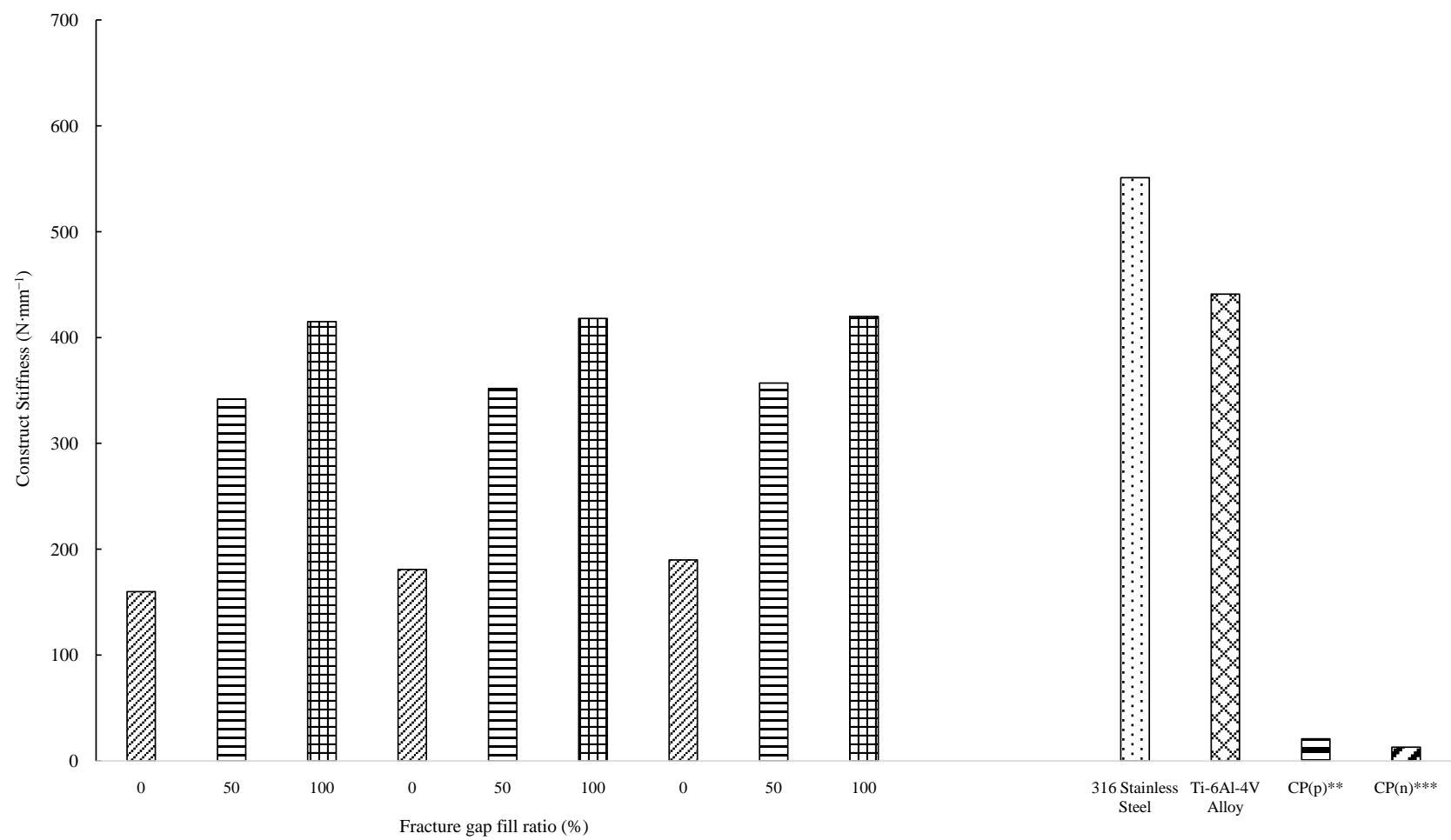

Figure 6. Summary of the construct stiffness values, under a compressive force of $100 \mathrm{~N}$. ${ }^{\star} \mathrm{E}=$ Modulus of elasticity; ${ }^{\star *} \mathrm{CP}(\mathrm{p})$ : Carbon fiber reinforced-PEEK composite; load parallel to fibers; ${ }^{\star *} \mathrm{CP}(\mathrm{n})$ : Carbon fiber reinforced-PEEK composite; load normal to fibers. 


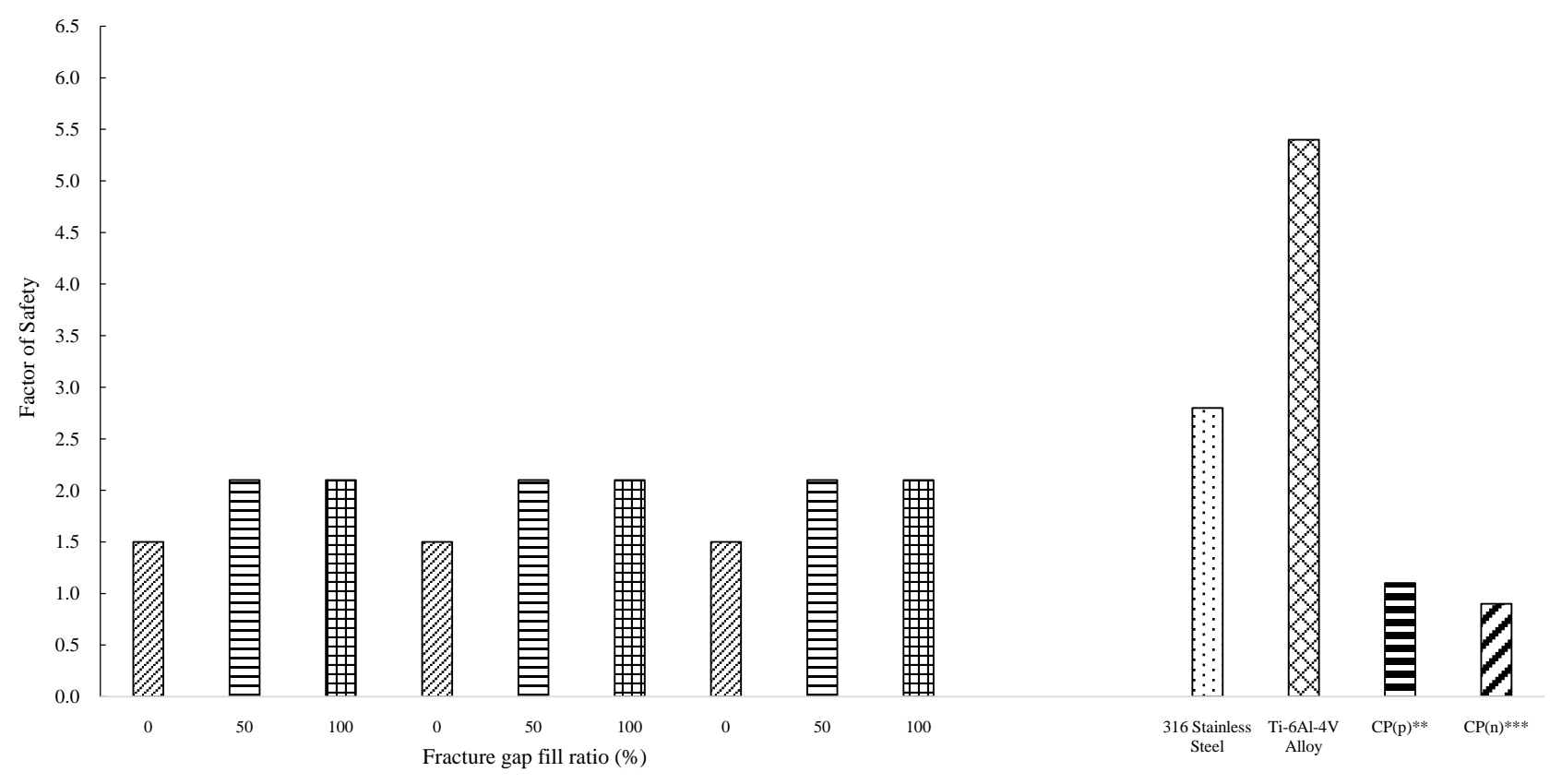

Figure 7. Summary of the computed factor of safety of the constructs, under compressive force of $100 \mathrm{~N}$. ${ }^{\star} \mathrm{E}=\mathrm{Modulus}$ of elasticity; ${ }^{\star \star} \mathrm{CP}(\mathrm{p})$ : Carbon fiber reinforced-PEEK composite; load parallel to fibers; ${ }^{\star * \star} \mathrm{CP}(\mathrm{n})$ : Carbon fiber reinforced-PEEK composite; load normal to fibers.

tendon(s), are often reported [10]. Thus, research continues for alternative surgical modalities to volar plating, such as the notional one (injectable bioresorbable polymer fixator) presented in the present work. It is pointed out that although there are balloon fracture reduction systems in current clinical use [5] [19], the present fixator differs from these systems in two ways. First, some of the current systems are not specifically designed for fixation of DRFs; thus, for example, they have been used in fixation of calcaneal fractures [19]. Second, and, more importantly, in many cases, reduction of the fracture by these current systems is followed by injection of a bone cement (usually, calcium phosphate cement) or an adjunctive hardware [5], whereas, in contrast, as envisaged, the present fixator will not require any such support.

Both the type and location of the simulated fracture pattern we used in the study (extra-articular metaphyseal fracture of the distal radius, with a planar gap of $4 \mathrm{~mm}$, positioned $25 \mathrm{~mm}$ below the distal surface) is clinically relevant because there are reports of patients presenting with this fracture pattern in emergency rooms, trauma centers, and hospitals [20].

The range of compression load used in the present work $(10 \mathrm{~N}-100 \mathrm{~N})$ is within the range of compressive force experienced in the metaphysis of the distal radius during grip tightening exercises performed as part of a rehabilitation regimen following surgical fixation of a DRF [21]. The assigned elastic moduli of the bioresorbable polymers used in the parametric studies of FIXATOR CONSTRUCT Model are within the range of those of bioresorbable polymers either used in an approved dorsal locking plate (Reunite ${ }^{\oplus}$; Biomet, Inc., Warsaw, IN, USA; co-polymer of poly(l, lactide) (PLLA) and poly (glycolic acid) (PGA) 
[22]), or been proposed for use in plates and screws in DRF plating systems (PLLA) [23], or proposed by the present workers for evaluation of the present fixator system (RESOMER ${ }^{\oplus}$; Sigma-Aldrich, St. Louis, MO, USA; co-polymer of PLLA and PGA) [24]. The three materials used in the parametric study of VOLAR PLATING CONSTRUCT Model are those that are used in the fabrication of volar locking plate systems used in current clinical work; for example 1) D-RAD SmartPack ${ }^{\circledast}$ (Smith \& Nephew Orthopaedics, Memphis, TN, USA; Ti-6Al-V alloy); 2) LCP (Synthes, West Chester, PA, USA; 316 stainless steel), and 3) DiPHOS-RM (Lima Corporate, Udine, Italy; carbon fiber-reinforced poly(etheretherketone)).

There are a number of applicable experimental studies published in the literature in which fractures in cadaveric distal radii were fixated using Ti alloy or stainless steel volar locking plate systems (see Table A1 in Appendix). Applicable literature studies are herein defined as ones that have the following characteristics: fracture type simulated and method of creation of the gap are each similar to those used in the present study; tested using fresh-frozen cadaver distal radii; loaded using a protocol that in whole or in part is the same as that used in the present study; and fixation using a Ti alloy or stainless steel volar plate that utilizes screws. However, two caveats are to be noted. First, in the present work, it was assumed that the bones were not osteoporotic, whereas, in some of the applicable literature studies, information was not given on the bone quality of the cadavers used [26] [27] [28] [32]. Second, the size of the gap of the simulated fracture in the present work is smaller than that in the aforementioned literature studies ( $4 \mathrm{~mm}$ versus $10-15 \mathrm{~mm}$ ). Keeping in mind these differences, the stiffnesses of the metal cases (Cases 1 and 2) in VOLAR PLATING CONSTRUCT Model (551 and $441 \mathrm{~N} \cdot \mathrm{mm}^{-1}$, respectively) are within the range of values reported in the aforementioned literature studies (see Table A1 in Appendix). This observation lends credence to the present results obtained using Volar Plating Construct and, by extension, to the present FIXATOR CONSTRUCT Model results. Furthermore, the stiffnesses of the FIXATOR CONSTRUCT Model cases are within the range of values reported in the aforementioned literature studies (see Table A1 in Appendix). It is also worth pointing out that the present FEA results buttress those obtained in our experimental biomechanical study of these two constructs [11].

There have been a number of literature FEA studies that include a model of the distal radius [33]-[41]; however, for five reasons, the results in the present work cannot be compared to those in any of these literature studies. First, in some of the literature studies, only a model of the intact distal radius was analyzed and the focus was determination of failure load of the distal radius [33] [34] or prediction of Colles' fracture load [35] [36]. In other words, these studies were conducted to investigate bone mechanics and fracture (especially, the role played by bone mineral density in these aspects) rather than within the context of evaluation of surgical fixation of DRFs. Second, in literature studies in which a model of the simulated fixated fractured distal radius was analyzed [33] [39] 
[40], with one exception [33], the investigations were on variants of a dorsal plating system [39] [40]. In the study of a volar plating system, Lin et al. [33] did not present results for stiffness of the construct. Third, an intact model was not included in any of the literature studies on fixation methods [33] [38] [39] [40] [41]. Fourth, there are no literature FEA studies that involve comparison of fixation using a volar plating system and one using a novel system. Fifth, there are no literature FEA studies on a volar plating system that included determination of the influence of the variables investigated in the present work on biomechanical parameters of the system.

Two principal findings in the present work are: 1) stiffness of Injectable Polymer Fixator Construct Model with fracture gap fill ratio $=100 \%$ (regardless of the assigned modulus of elasticity of the polymer) is comparable to that of a construct model that contains a Ti-6Al-4V alloy volar locking plate; and 2) computed factor of safety of Injectable Polymer Fixator Construct Model that has a fracture gap fill ratio $=50 \%$ or $100 \%$ (regardless of the modulus of elasticity of the polymer) is comparable to that of a construct model that contains a stainless steel volar locking plate. These results suggest that the Injectable Polymer Fixator system may be a plausible alternative to a metal volar locking plate. The aforementioned principal findings point to a potential challenge in the clinical use of the injectable polymer fixator, which is to ensure that a fracture gap fill ratio of at least $50 \%$ is obtained. Discussion of suggestions of methods to achieve this is outside the ambit of the present study.

The present study has a number of limitations. First, the solid model of the intact distal radius was constructed using a statistically-averaged solid model that comprised only the cortical bone. Thus, we manually created, from this model, the cortical bone shell and the cancellous bone core. Even though the demarcation between these two types of bone was in conformity with published literature information, we recognize that the final geometry obtained using this approach is likely to be less accurate than if the geometry were obtained from, say, computed tomography scans of the distal radius of a person. Second, in the solid model of the distal radius, the dorsal wall of the cortical shell was retained, although, in some fracture patterns, such as AO/OTA A3 fracture, this is not the case [42]. Third, the solid model of the intact distal radius did not include any of the contiguous soft tissues, such as the radioscaphocapitate ligament. Fourth, simplifications were used in the constitutive material models for the bones and the bioresorbable polymer. The cortical and cancellous bones were each treated as linear elastic materials, when either 1) each of these bones could be modeled as transversely isotropic materials [14]; or 2) high-resolution peripheral quantitative computed tomography Hounsfield number (HU) could be obtained for bone at various locations in the model and, then, a relationship between $\mathrm{HU}$ and bone properties could be used to determine bone properties [33] [36] [37]. A bioresorbable polymer was treated as linear elastic material when, in fact, it is nonlinear. Fifth, only one volar locking plate design was used, whereas, there are many designs used in clinical practice, with differences between them being in 
features such as plate cross-sectional dimensions (length, width, and thickness), screw dimensions (diameter and length), number of screws, location of screws on the plate, and angulation of the distal head of the plate and of the holes relative to the longitudinal axis of the radius. Each of these variables impacts the biomechanical responses of a construct that contains the plate. Sixth, quasi-static compression load was used, whereas, in many activities of daily living, the distal radius is subject to complex and fluctuating loading. Seventh, in computing factor of safety, we used the von Mises failure criterion. While this criterion is appropriate in the case of Ti-6Al-4V alloy and stainless steel, for a bioresorbable polymer, an alternative criterion, such as a hierarchical multiscale model [43], may be preferred but the material property values needed to use this model are not available in the literature. The reason that we used the aforementioned limitations is that the purpose of our study was to compare biomechanical performance of models of a construct that included the fixator versus one that included the volar locking plate, with all other applicable parameters being the same.

We postulate theoretical clinical advantages of the proposed injectable bioresorbable polymer fixator over a volar plating system, such as being minimally invasive, allowing percutaneous pinning, easier to use in osteoporotic patients, having greater rotational stability, and incurring lower cost. At the same time, we recognize that the plausibility of the fixator will only be established through in vivo evaluation in a suitable animal model and, ultimately, in a clinical study. Such work will allow issues, such as the effect of off-center positioning of the intramedullary rod in the intramedullary canal on stability of the fixator, extent of reduction of dorsal or volar angulation achieved, determination of acceptable operational conditions for intra-operative fluoroscopy (radiation dose and exposure duration), and implication of resorbability of the fixator for long-term healing of the fracture, to be examined in a systematic manner.

\section{Conclusion}

For simulated surgical treatment of a planar distal radius fracture, FEA was used to conduct a biomechanical comparison when a model of a notional novel fixator was used versus when a model of volar plating was used. A distinguishing feature of the study was determination of the influence of two characteristics of the fixator (modulus of elasticity of the polymer and the fracture gap fill ratio) and one characteristic of the volar plate (modulus of elasticity of the material of the plate and the screws) on stiffness and factor of safety of the model constructs. In future studies on these aspects, dynamic loading should be applied because it is the type of loading that is experienced at the distal radius during many activities of daily living.

\section{References}

[1] Nellans, K.W., Kowalski, E. and Chung, K.C. (2012) The Epidemiology of Distal Radius Fractures. Hand Clinics, 28, 113-125. 
https://doi.org/10.1016/j.hcl.2012.02.001

[2] Zhang, L.-H., Wang, Y.-N., Zhi, M., Zhang, L.-C., Li, H.-D., Huan, Y., Kiu, X.-X. and Tang, P.-F. (2015) Volar Locking plate versus External Fixation for the Treatment of Unstable Distal Radial Fractures: A Meta-Analysis of Randomized Controlled Trials. Journal of Surgical Research, 193, 324-333.

https://doi.org/10.1016/j.jss.2014.06.018

[3] Brogren, E., Petranek, M. and Atroshi, I. (2015) Cast-Treated Distal Radius Fractures: A Prospective Cohort Study of Radiological Outcomes and Their Association with Impaired Calcaneal Bone Mineral Density. Archives of Orthopaedic and Trauma Surgery, 135, 927-933. https://doi.org/10.1007/s00402-015-2220-z

[4] Shah, R., Shah, S., Shah, A., Gajjar, S., Chaudhari, V. and Siddhapuria, P. (2017) Comparison Study for Internal and External Modes of Fixation for Fractures of Distal End Radius. International Journal of Research in Orthopaedics, 3, 744-750. https://doi.org/10.18203/issn.2455-4510.IntJResOrthop20172032

[5] Gausepohl, T., Penning, D., Heck, S., Gick, S., Vegt, P.A. and Block, J.E. (2017) Effective Management of Bone Fractures with the Illuminoss ${ }^{\circledast}$ Photodynamic Bone Stabilization System: Initial Clinical Experience from the European Union Registry. Orthopedic Reviews (Pavia), 9, 6988. https://doi.org/10.4081/or.2017.6988

[6] Hull, P., Baraza, N., Whalley, H., Brewster, M. and Costa, M. (2010) Dorsally Displaced Fractures of the Distal Radius-A Study of Preferred Treatment Options among UK Trauma and Orthopedic Surgeons. Hand Surgery, 15, 185-191. https://doi.org/10.1142/S0218810410004801

[7] Lichtman, D.M., Bindra, R.R., Boyer, M.I., Putnam, M.D., Ring, D., Slutsky, D.J., et al. (2011) American Academy of Orthopaedic Surgeons Clinical Practice Guideline on: The Treatment of Distal Radius Fractures. Journal of Bone \& Joint Surgery American Volume, 93, 775-778. https://doi.org/10.2106/JBJS.938ebo

[8] Horst, T.A. and Jupiter, J.B. (2016) Stabilisation of Distal Radius Fractures: Lessons Learned and Future Directions. Injury, 47, 313-319. https://doi.org/10.1016/j.injury.2015.09.030

[9] Vosbikian, M., Ketonis, C., Huang, R. and Ilyas, A.M. (2016) Optimal Positioning for Volar Plate Fixation of a Distal Radius Fracture. Orthopedic Clinics of North America, 47, 235-244. https://doi.org/10.1016/j.ocl.2015.08.020

[10] Satake, H., Hanaka, N., Honma, R., Watanabe, T., Inoue, S., Kanauchi, Y., Kato, Y., Nakajima, T., Sato, D., Maruyama, M., Naganuma, Y., Sasaki, J., Toyono, S., Harada, M., Ishigaki, D., Takahara, M. and Takagi, M. (2016) Complications of Distal Radius Fractures Treated by Volar Locking Plate Fixation. Orthopedics, 39, e893-e896. https://doi.org/10.3928/01477447-20160517-05

[11] Zysk, A., Lewis, G., Taxier, D. and Rose, J. (2017) Biomechanical Comparison of Prototype of a Novel Intramedullary Injectable Bioresorbable Polymer-Bioresorbable Balloon Osteosynthesis and a Volar Locking Plate for Treatment of Distal Radius Fractures. World Journal of Engineering and Technology, 5, 309-323.

[12] Smith \& Nephew (2016) Memphis, TN, USA; Private Communication.

[13] Rausch, S., Klos, K., Gras, F., Skuley, H., Popp, A., Hofman, G., et al. (2013) Utility of the Cortical Thickness of the Distal Radius as a Predictor of Distal Radius Bone Density. Archives of Trauma Research, 2, 11-15. https://doi.org/10.5812/atr.10687

[14] Rho, R.Y. (2000) Ultrasonic Methods for Evaluating Mechanical Properties of Bone. In: An, Y.H. and Draughn, R.A., Eds., Mechanical Testing of Bone and the Bone-Implant Interface, CRC Press, Boca Raton, 357-370.

[15] Smith, W.F. and Hashemi, J. (2006) Foundations of Materials Science and Engi- 
neering. 4th Edition, McGraw Hill Educational, New York.

[16] Rasheva, Z., Zhang, G. and Burkhart, T. (2010) A Correlation between the Tribological and Mechanical Properties of Carbon Fibers Reinforced PEEK Materials with Different Fiber Orientations. Tribology International, 43, 1430-1437.

[17] Hart, A., Collins, M., Chhatwal, D., Steffen, T., Harvey, E. and Martineau, P. (2015) Can the Use of Variable-Angle Volar Locking Plates Compensate for Suboptimal Plate Positioning in Unstable Distal Radius Fractures? A Biomechanical Study. Journal of Orthopaedic Trauma, 29, 1-6. https://doi.org/10.1097/BOT.0000000000000146

[18] Marshall, T., Momaya, A., Eberhardt, A., Chaudhari, N. and Hunt III, T.R. (2015) Biomechanical Comparison of Volar Fixed-Angle Locking Plates for AO C3 Distal Radius Fractures: Titanium Plates versus Stainless Steel with Compression. Journal of Hand Surgery, 40, 2032-2038.

[19] Vittore, D., Vicenti, G., Caizzi, G., Abate, A. and Moretti, B. (2014) Balloon-Assisted Reduction, Pin Fixation, and Tricalcium Phosphate Augmentation for Calcanear Fracture. Injury, 45, 572-579.

[20] Plate, J.F., Gaffney, D.L., Emory, C.L., Mannava, S., Smith, B.P., Koman, A., Wiesler, E.R. and Li, Z. (2015) Randomized Comparison of Volar Locking Plates and Intramedullary Nails for Unstable Distal Radius Fractures. Journal of Hand Surgery, 40, 1095-1101.

[21] Obert, L., Loisel, F., Gasse, N. and Lepage, D. (2015) Distal Radius Anatomy Applied to the Treatment of Wrist Fractures by Plate: A Review of Recent Literature. SICOT-J, 1, 14. https://doi.org/10.1051/sicotj/2015012

[22] Gangopadhyay, S., Ravi, K. and Packer, G. (2006) Dorsal Plating of Unstable Distal Radius Fractures using a Bio-Absorbable Plating System and Bone Substitute. Journal of Hand Surgery, 31B, 93-100.

[23] Rikli, D.A., Curtis, R., Schilling, C. and Goldhahn, J. (2002) The Potential of Bioresorbable Plates and Screws for Distal Radius Fracture Fixation. Injury, 33, S-B77-S-B83.

[24] RESOMER Biodegradable Polymer for Medical Device Applications. Brochure; Sigma Aldrich, St. Louis.

http://www.sigmaaldrich.com/materials-science/polymer-science/resomer.html

[25] Osada, D., Viegas, S.F., Shah, M.A., Morris, R.P. and Patterson, R.M. (2003) Comparison of Different Distal Radius Dorsal and Volar Fracture Fixation Plates: A Biomechanical Study. Journal of Hand Surgery, 28A, 94-104. https://doi.org/10.1053/jhsu.2003.50016

[26] Liporace, F.A., Gupta, S., Jeong, G.K., Stracher, M., Kummer, F., Egol, K.A. and Koval, K.J. (2005) A Biomechanical Comparison of a Dorsal 3.5-mm T-Plate and a Volar Fixed-Angle Plate in a Model of Dorsally Unstable Distal Radius Fractures. Journal of Orthopaedic Trauma, 19, 187-191. https://doi.org/10.1097/00005131-200503000-00006

[27] Blythe, M., Stoffel, K., Jarrett, P. and Kuster, M. (2006) Volar versus Dorsal Locking Plates with and without Radial Styloid Locking Plates for Fixation of Dorsally Comminuted Distal Radius Fractures: A Biomechanical Study in Cadavers. Journal of Hand Surgery, 31A, 1587-1593.

[28] Strauss, E.J., Banerjee, D., Kummer, F.J. and Tejwani, N.C. (2008) Evaluation of a Novel, Nonspanning External Fixator for Treatment of Unstable Extra-Articular Fractures of the Distal Radius: Biomechanical Comparison with a Volar Locking Plate. Journal of Trauma, 64, 975-981. 
https://doi.org/10.1097/TA.0b013e3180eea9f0

[29] Mehling, I., Müller, L.P., Delinsky, K., Mehler, D., Ing, D., Burkhart, K.J., et al. (2010) Number and Locations of Screw Fixation for Volar Fixed-Angle Plating of Distal Radius Fractures: Biomechanical Study. Journal of Hand Surgery, 35A, 885-891.

[30] Mehling, I., Klitscher, D., Mehling, A.P., Nowak, T.E., Sternstein, W., Ing, D., et al. (2012) Volar Fixed-Angle Plating of Distal Radius Fractures: Screws versus Pegs-A Biomechanical Study in a Cadaveric Model. Journal of Orthopaedics and Traumatology, 26, 395-401. https://doi.org/10.1097/BOT.0b013e318225ea46

[31] Baumbach, S.F., Synek, A., Traxler, H., Mutschler, W., Pahr, D. and Chevalier, Y. (2015) The Influence of Distal Screw Length on the Primary Stability of Volar Plate Osteosynthesis-A Biomechanical Study. Journal of Orthopaedic Surgery and Research, 10, 139.

[32] Koh, S., Morris, R.P., Patterson, R.M., Kearney, J.P., Buford, W.L. and Viegas, S.F. (2006) Volar Fixation for Dorsally Angulated Extra-Articular Fractures of the Distal Radius: A Biomechanical Study. Journal of Hand Surgery, 31A, 771-779.

[33] Lin, Y.-H., Lin, C.-L., Kuo, H.-N., Sun, M.-T. and Chen, A.C.-Y. (2012) Biomechanical Analysis of Volar and Dorsal Double Locking Plates for Fixation in Comminuted Extra-Articular Distal Radius Fractures: A 3D Finite Element Study. Journal of Medical and Biological Engineering, 32, 349-356.

https://doi.org/10.5405/jmbe.1003

[34] Pistoia, W., Rietbergen, B.V., Lochmüller, E.M., Lill, C.A., Eckstein, F. and Rüegsegger, P. (2002) Estimation of Distal Radius Failure Load with Micro-Finite Element Analysis Models Based on Three-Dimensional Peripheral Quantitative Computed Tomography Images. Bone, 30, 842-848.

[35] Troy, K.L. and Grabiner, M.D. (2007) Off-Axis Loads Cause Failure of the Distal Radius at Lower Magnitudes than Axial Loads: A Finite Element Analysis. Journal of Biomechanics, 40, 1670-1675.

[36] Varga, P., Baumbach, S., Pahr, D. and Zysset, P.K. (2009) Validation of an Anatomy Specific Finite Element Model of Colles' Fracture. Journal of Biomechanics, 42, 1726-1731.

[37] Hosseini, H.S., Dunki, A., Fabech, J., Stauber, M., Vilayphiou, N., Pahr, D., Pretterklieber, M., Wandel, J., van Rietbergen, B. and Zysset, P.K. (2017) Fast Estimation of Colles' Fracture Load of the Distal Section of the Radius by Homogenized Finite Element Analysis Based on HR-pQCT. Bone, 97, 65-75.

[38] Varga, P., Pahr, D.H., Baumbach, S. and Zysset, P.K. (2010) HR-pQCT Based FE Analysis of the Most Distal Radius Section Provides an Improved Prediction of Colles' Fracture Load in Vitro. Bone, 47, 982-928.

[39] Lin, C.-L., Lin, Y.-H. and Chen, A.C.-Y. (2006) Buttressing Angle of the Double-Plating Fixation of a Distal Radius Fracture: A Finite Element Study. Medical \& Biological Engineering \& Computing, 44, 665-673. https://doi.org/10.1007/s11517-006-0082-9

[40] Cheng, H.-Y.K., Lin, C.-L., Lin, Y.-H. and Chen, A.C.-Y. (2007) Biomechanical Evaluation of the Modified Double-Plating Fixation for the Distal Radius Fracture. Clinical Biomechanics, 22, 510-517.

[41] Chen, A.C.-Y., Lin, Y.-H., Kuo, H.-N., Yu, T.-C., Sun, M.-T. and Lin, C.-L. (2013) Design Optimisation and Experimental Evaluation of Dorsal Double Plating Fixation for Distal Radius Fracture, Injury, 44, 527-534.

[42] Brogren, E., Petranek, M. and Atroshi, I. (2007) Incidence and Characteristics of 
Distal Radius Fractures in a Southern Swedish Region. BMC Musculoskeletal Disorders, 8, 48. https://doi.org/10.1186/1471-2474-8-48

[43] Vu-Bac, N., Areias, P.M.A. and Rabczuk, T. (2016) A Multiscale Multisurface Constitutive Model for the Thermoplastic Behavior of Polyethylene. Polymer, 105, 327-338. 


\section{Appendix}

Table A1. Summary of some features of relevant literature biomechanical studies involving testing of constructs comprising a fresh-frozen cadaveric distal radius with a simulated fracture and a fixed-angle metal volar locking plate and results for compressive longitudinal stiffness.

\begin{tabular}{|c|c|c|c|c|}
\hline Fracture type simulated & $\begin{array}{l}\text { Method of creation } \\
\text { of simulated fracture }\end{array}$ & Loading protocol & Construct stiffness $\left(\mathrm{N} \cdot \mathrm{mm}^{-1}\right)$ & Ref. \# \\
\hline $\begin{array}{l}\text { Extra-articular, } \\
\text { severe } \\
\text { comminuted fracture }\end{array}$ & $\begin{array}{l}\text { 10-mm gap } \\
\text { (10 mm volar height, } \\
10 \mathrm{~mm} \text { dorsal height, } \\
10 \mathrm{~mm} \text { radial height, } \\
10 \mathrm{~mm} \text { ulnar height }) \\
20 \mathrm{~mm} \text { from the } \\
\text { distal articular surface }\end{array}$ & $\begin{array}{l}\text { Loaded, at } 2 \mathrm{~mm} \cdot \mathrm{s}^{-1} \text {, } \\
\text { to failure in } \\
\text { axial compression }\end{array}$ & $\begin{array}{l}107 \pm 32 \text { (Tiplate) } \\
210 \pm 34 \text { (Steel plate) }\end{array}$ & $\begin{array}{l}\text { Osada } \\
\text { et al. [25] }\end{array}$ \\
\hline $\begin{array}{l}\text { Comminuted, } \\
\text { extra-articular, } \\
\text { dorsally-unstable fracture }\end{array}$ & $\begin{array}{l}\text { Osteotomy created } \\
20 \text { mm proximal to the } \\
\text { articular surface at the } \\
\text { Lister tubercle; } \\
\text { then, 6-mm-wide } \\
\text { dorsally-based } \\
\text { wedge removed }\end{array}$ & $\begin{array}{l}\text { Axial compression, } \\
\text { at } 1 \mathrm{~N} \cdot \mathrm{s}^{-1} \text {, to a } \\
\text { maximum load of } 90 \mathrm{~N}\end{array}$ & $\begin{array}{l}430 \pm 200 \text { (Tiplate; load } \\
\text { applied at centera) } 340 \pm 140 \\
\text { (Ti plate; load applied radial off-center) } \\
440 \pm 200 \text { (Ti plate; load applied ulnar } \\
\text { off-center) } 250 \pm 110 \text { (Ti plate; load } \\
\text { applied volar off-center) } 150 \pm 92 \\
\text { (Ti plate; load applied dorsal off-center) }\end{array}$ & $\begin{array}{l}\text { Liporace } \\
\text { et al. [26] }\end{array}$ \\
\hline $\begin{array}{l}\text { Dorsally-comminuted } \\
\text { fracture }\end{array}$ & $\begin{array}{l}\text { An incomplete } 1-\mathrm{mm} \\
\text { wide dorsal } \\
\text { wedge osteotomy } \\
\text { that started } 20 \mathrm{~mm} \text { from } \\
\text { the articular surface }\end{array}$ & $\begin{array}{l}\text { Cyclically loaded, } \\
\text { at } 100 \mathrm{~N} \cdot \mathrm{s}^{-1}, \text { from } \\
\text { preload of } 100 \mathrm{~N} \text { to a } \\
\text { compression load } \\
\text { of } 250 \mathrm{~N} \text {. Either } 5000 \text { or } \\
20,000 \text { cycles at } 1 \mathrm{~Hz}\end{array}$ & $400 \pm 100$ & $\begin{array}{l}\text { Blythe } \\
\text { et al. [27] }\end{array}$ \\
\hline $\begin{array}{l}\text { Severely comminuted, } \\
\text { unstable, } \\
\text { extra-articular fracture }\end{array}$ & $\begin{array}{l}\text { Transverse osteotomy } \\
20 \mathrm{~mm} \text { proximal to the ar- } \\
\text { ticular surface; then, } \\
15 \text {-mm fracture gap } \\
\text { created, making a } \\
\text { second transverse } \\
\text { osteotomy } 15 \mathrm{~mm} \\
\text { proximal to the } \\
\text { initial osteotomy }\end{array}$ & $\begin{array}{l}\text { Axial compression, } \\
\text { at } 1 \mathrm{~N} \cdot \mathrm{s}^{-1}, \text { to a maximum } \\
\text { load of } 50 \mathrm{~N}\end{array}$ & $\begin{array}{l}460 \pm 10 \text { (Ti plate; load applied at } \\
\text { central location }{ }^{\text {a }} 150 \pm 2 \text { (Ti plate; } \\
\text { load applied at dorsal location) } \\
240 \pm 3 \text { (Ti plate; load applied } \\
\text { at volar location) }\end{array}$ & $\begin{array}{l}\text { Strauss } \\
\text { et al. }[28]\end{array}$ \\
\hline $\begin{array}{l}\text { Extra-articular } \\
\text { AO-type A3 fracture }\end{array}$ & $\begin{array}{l}\text { Excision of } 10-\mathrm{mm} \text { wide } \\
\text { bone segment, centered } \\
20 \mathrm{~mm} \text { proximal to the } \\
\text { tip of the radial styloid }\end{array}$ & $\begin{array}{l}\text { Static axial } \\
\text { compression } \\
\text { force of } 250 \mathrm{~N}\end{array}$ & $\begin{array}{l}83 \pm 62 \text { (Ti plate; } 4 \text { locking screws } \\
\text { in the distal row of the plate) } 208 \pm 60 \\
\text { (Ti plate; } 4 \text { locking screws alternately in } \\
\text { the distal and proximal rows of the plate) } \\
178 \pm 82 \text { (Ti plate; } 3 \text { locking screws in the } \\
\text { proximal row of the plate) } 429 \pm 224 \\
\text { (Ti plate; } 7 \text { locking screws filling all } \\
\text { screw hoes in the distal and } \\
\text { proximal rows of the plate) }\end{array}$ & $\begin{array}{l}\text { Mehling } \\
\text { et al. [29] }\end{array}$ \\
\hline $\begin{array}{l}\text { Extra-articular } \\
\text { OTA-type 23-A3 fracture }\end{array}$ & $\begin{array}{l}\text { Excision of } 10-\mathrm{mm} \text { wide } \\
\text { dorsal wedge, centered } 20 \\
\mathrm{~mm} \text { from the articular } \\
\text { margin of the distal radius }\end{array}$ & $\begin{array}{l}\text { Static axial compression } \\
\text { force of } 130 \mathrm{~N}\end{array}$ & $\begin{array}{l}188 \pm 53 \text { (Ti plate; } 4 \text { locking screws in } \\
\text { the distal row of the plate and } 3 \text { locking } \\
\text { screws in the proximal row of the plate }\end{array}$ & $\begin{array}{l}\text { Mehling } \\
\text { et al. [30] }\end{array}$ \\
\hline $\begin{array}{l}\text { Extra-articular } \\
\text { OTA-type } 23 \text { A3 fracture }\end{array}$ & $\begin{array}{l}\text { A dorsal wedge } \\
\text { osteotomy, completely } \\
\text { separating the volar } \\
\text { cortex ( } 1 \mathrm{~mm} \text { gap) }\end{array}$ & $\begin{array}{l}\text { Static axial compression } \\
\text { force, at } 1 \mathrm{~mm} \cdot \mathrm{s}^{-1} \text {, } \\
\text { until either a } 20 \% \\
\text { drop in force or } 3 \mathrm{~mm} \\
\text { displacement reached }\end{array}$ & $\begin{array}{l}706 \pm 103 \text { (Ti plate; distal screw tips are } \\
\text { flushed with or just short of the } \\
\text { distal cortex [Group A] } 660 \pm 124 \\
\text { (Ti plate; target screw length of } 75 \% \text { of } \\
\text { that achieved in Group A construct) }\end{array}$ & $\begin{array}{l}\text { Baumbach } \\
\text { et al. [31] }\end{array}$ \\
\hline
\end{tabular}




\section{Continued}

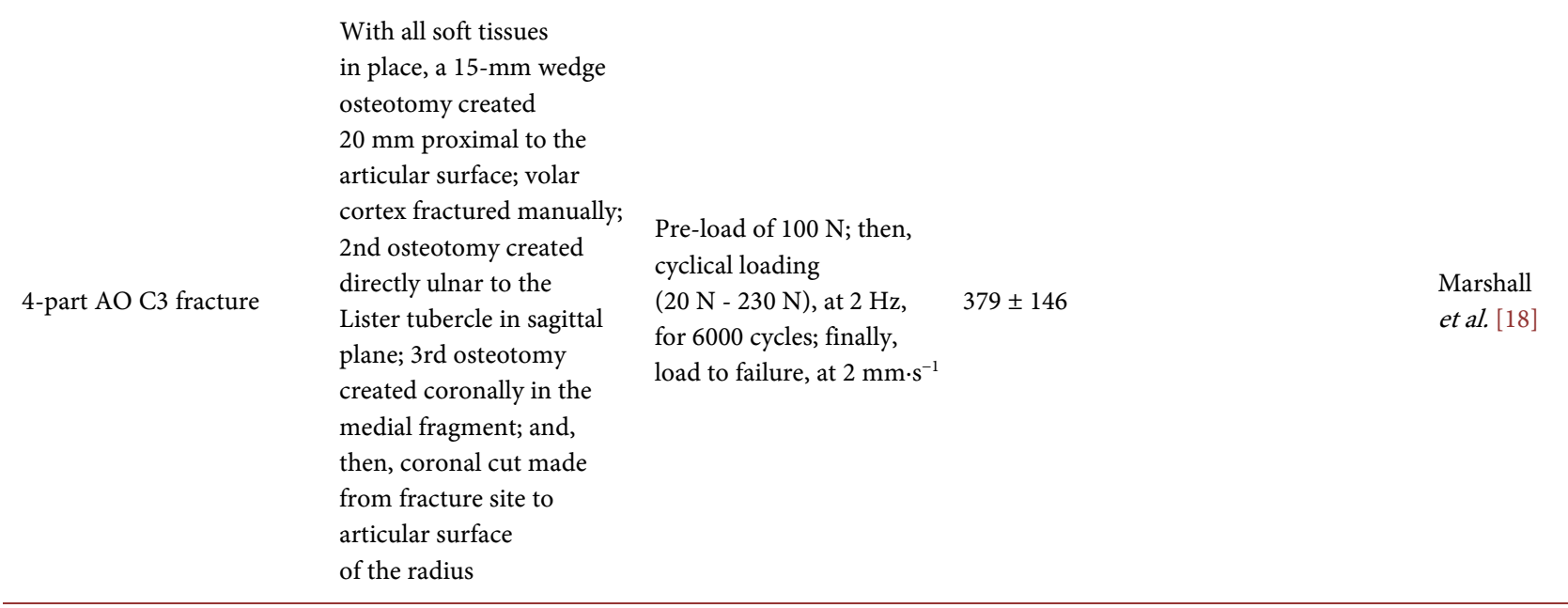

